\title{
Gross-total resection of temporal low grade gliomas is a critically important factor in achieving seizure-freedom
}

\author{
A ressecção total de gliomas temporais de baixo grau é um importante fator no controle \\ das crises convulsivas \\ Lucas Crociati Meguins', Rodrigo Antônio Rocha da Cruz Adry’, Sebastião Carlos da Silva Júnior', Carlos \\ Umberto Pereira ${ }^{2}$, Jean Gonçalves de Oliveira ${ }^{3,4}$, Dionei Freitas de Morais ${ }^{1}$, Gerardo Maria de Araújo Filho ${ }^{5}$, \\ Lúcia Helena Neves Marques ${ }^{6}$
}

\begin{abstract}
Objective: To present a surgical series of patients with low grade temporal gliomas causing intractable epilepsy, focusing on long-term seizure outcome. Method: A retrospective study was conducted with patients with temporal low-grade gliomas (LGG). Results: Sixty five patients with were operated in our institution. Males were more affected than females and the mean age at surgery was $32.3 \pm 8.4$ (9-68 years). The mean age at seizure onset was 25.7 \pm 9.2 (11-66 years). Seizure outcome was classified according with Engel classification. After one year of follow up, forty two patients (64.6\%) were Engel I; seventeen (26.2\%) Engel II; four (6.2\%) Engel III and two (3.1\%) Engel IV. Statistically significant difference in seizure outcome was obtained when comparing the extension of resection. Engel I was observed in 39 patients (69.6\%) with total resection and in only 3 (33.3\%) patients with partial resection. Conclusion: Gross-total resection of temporal LGGs is a critically important factor in achieving seizure-freedom.
\end{abstract}

Keywords: temporal low-grade gliomas, intractable epilepsy, long-term seizure outcome.

\section{RESUMO}

Objetivo: Apresentar uma série cirúrgica de pacientes com gliomas temporais de baixo grau, causando epilepsia de difícil controle. Método: Estudo retrospectivo de pacientes com diagnóstico de glioma temporal de baixo grau temporais. Resultados: 65 pacientes com foram operados em nossa instituição. A média de idade de início das crises foi de 25,7 \pm 9,2 (11-66 anos). Após um ano de acompanhamento, quarenta e dois pacientes (64,6\%) estavam Engel I; dezessete (26,2\%) Engel II; quatro (6,2\%) Engel III e dois (3,1\%) Engel IV. Houve diferença estatisticamente significativa no resultado do controle das crises quando se compara a extensão da ressecção. Engel I foi observada em 39 pacientes (69,6\%) com a ressecção total e em apenas 3 (33,3\%) pacientes com ressecção parcial. Conclusão: A ressecção total de glioma temporal de baixo grau temporais é um fator extremamente importante no controle das crises.

Palavras-chave: glioma temporal de baixo grau, epilepsia de difícil controle, controle das crises.

Epileptic seizures are a common manifestation of brain tumors, frequently the presenting symptom and the main factor influencing quality of life ${ }^{1,2,3}$. The incidence of tumors in patients with chronic epilepsy has been reported to range from $10 \%$ to $50 \%{ }^{4,5}$. Among these, low-grade gliomas (LGG) are the most common, with a variety of other histological entities reported ${ }^{6}$. Almost two-thirds of patients with supratentorial gliomas had seizures ${ }^{7}$. Although the precise nature of epileptogenesis is still unclear, glutamate release by glioma cells has recently been shown as a possible cause of seizures ${ }^{8}$ and slowly progressive tumors near the cortex are described to be associated with a high incidence of seizures?

\footnotetext{
${ }^{1}$ Faculdade de Medicina de São José do Rio Preto, Hospital de Base, Departamento de Ciências Neurológica, Divisão de Neurocirurgia, São José do Rio Preto SP, Brazil; Universidade Federal de Sergipe, Departamento de Medicina, Aracaju SE, Brazil;

${ }^{3}$ Universidade Nove de Julho, Faculdade de Medicina, Departamento de Ciências Medicas, Divisão de Neurocirurgia, São Paulo SP, Brazil;

${ }^{4}$ Hospital Beneficência Portuguesa de São Paulo, Centro de Neurologia e Neurocirurgia Associadas, Departamento de Cerebrovascular e Cirurgia da Base do Crânio, São Paulo SP, Brazil;

${ }^{5}$ Faculdade de Medicina de São José do Rio Preto, Departamento de Psiquiatria e Medicina Psicológica, São Paulo SP, Brazil;

${ }^{6}$ Faculdade de Medicina de São José do Rio Preto, Hospital de Base, Departamento de Ciências Neurológica, Divisão de Neurologia, São José do Rio Preto SP, Brazil. Correpondence: Lucas Crociati Meguins; Rua Pedro Palotta, 101/31B; 15092-205 São José do Rio Preto SP, Brasil; E-mail: lucascrociati@hotmail.com Conflict of interest: There is no conflict of interest to declare.

Received 12 April 2015; Received in final form 03 July 2015; Accepted 23 July 2015.
} 
Resection is often recommended to patients with epileptic seizures harboring a brain tumor. Clinical studies from several epilepsy centers specifically report favorable seizure outcome in patients who had surgery on temporal LGG $\mathrm{L}^{10,11,12,13}$. However, unfortunately there is still no standard surgical approach, with some authors advocating lesionectomy alone and others arguing for more extensive resection ${ }^{10,11,12,13,14}$. The aim of the current investigation is to present a surgical series of patients with temporal LGG causing intractable epilepsy, focusing on long-term seizure outcome.

\section{METHOD}

\section{Study delineation}

A retrospective observational investigation was conducted with data collection from all patients treated in the epilepsy clinic of a Brazilian tertiary referral center. Patients selected were diagnosed with temporal LGG from January 1995 to March 2013. Clinical data were obtained retrospectively. For all patients with the diagnosis of temporal LGG on magnetic resonance images (MRI), the following data were collected: gender, age at surgery, handedness, type and number of antiepileptic drugs (AEDs) used and results of formal neuropsychological evaluations. The present study was approved by the Ethical Committee of our institution.

Patients with temporal LGG were included in the present investigation when fulfilling all the following criteria: (1) temporal lobe involvement only; (2) presence of preoperative MRI, neurophysiologic investigation with video-electroencephalogram (EEG) and neuropsychological assessment; (3) at least 1 year of clinical and radiological follow-up and (4) patients operated by an epilepsy surgeon with the same surgical strategy.

\section{Pre-surgical evaluation}

Patients were submitted to video-EEG monitoring using the Neuro Workbench software and a Nihon Kohden hardware. Every patient was analyzed by an experienced epileptologist as an integral part of inpatient assessment.

All patients were submitted to a neuropsychological assessment pre- and post-surgically (at 12 months). Verbal memory was assessed by a list of learning design, and figural memory by a design learning test using independent items. Memory deficits were defined as performance one standard deviation below of the normal performance of age-matched controls.

Brain MRI was obtained accordingly with a specific epilepsy protocol using a 1.5 Tesla Scanner. All MRIs were analyzed by an experienced neuroradiologist that confirmed the radiological diagnosis of temporal lobe LGG. Location of the tumor was divided into (1) mesial - mesial to the collateral sulcus (mainly the parahippocampal gyrus, hippocampus, amigdalum and uncus); (2) lateral - all structures lateral to the collateral sulcus and (3) whole temporal lobe - if both mesial and lateral parts were involved. All patients had MRI within 72 hours of surgery and in every year of follow-up. MRI was also obtained in order to see any recurrence.

The surgical extension of resection on temporal lobe LGG mainly depended on two factors: (1) proximity or involvement of mesial structures and (2) hemispheric dominance. The standard surgical approach on non-dominant hemispheres was anterior temporal resection with amygdalohippocampectomy whether the mesial structures were involved or not. However, on the dominant hemisphere the surgical approach mainly depended on neuropsychological testing: extended lesionectomy was performed if mesial structures were not involved and only partial resection when mesial structures were involved due to the high risk of severe memory problems.

Biopsy specimens were collected from all patients with chronic drug-resistant and radiological evidence of temporal LGG, who underwent surgical treatment. Standardized neuropathological analysis was performed in all patients under study. Surgical specimens submitted for neuropathological evaluation were microscopically analyzed by using hematoxylin-eosin staining. The pathologist reported their findings without clinical or imaging data.

\section{Outcome assessments and follow-up}

Follow-up investigations were carried out in operated patients. At the 12 months follow-up, all patients received a neurological examination including observation of behavior disorders, exploration of seizure outcome and a cerebral 1.5 Tesla MRI. Seizure outcome was classified according with Engel classification ${ }^{15}$.

\section{Statistical analysis}

Averages are expressed as the mean \pm standard deviation (SD) for parametric data and as median values for nonparametric data. Statistical analysis was performed utilizing the Fisher's exact test. Long-term seizure outcome and surgical survival rate was assessed using Kaplan-Meier curves. A p-value $<0.05$ was considered statistically significant.

\section{RESULTS}

A total of 69 patients with medically intractable epilepsy and pathologically confirmed tumors were identified and operated. Four patients were excluded from this sample because they did not reach a minimum one year of follow up.

Table 1 shows the clinical findings of 65 patients operated with temporal LGG.

Table 2 shows the summary of surgical findings of 65 patients operated with temporal LGG. We preferably performed total resection in order to have favorable seizure outcome and to decrease the chance of recurrence and tumor 
upgrade. On the right side, anterior temporal lobe resection with amygdalohippocampectomy was generally preferred. On the left hemisphere (generally dominant), we commonly respected the mesial structures due to the risk of severe memory. We had 9 patients $(13.8 \%)$ in whom partial resection was performed due to the dominance of memory, although tumor involvement was documented. They are still under follow-up without any clinical or radiological deterioration. Two cases (3.1\%) needed reoperation because of tumor recurrence, one patient with diffuse astrocytoma and one patient with oligodendroglioma.

Table 3 shows the summary of seizure outcome of 65 patients operated with temporal LGG. The seizure-free survival rate of our series over time was illustrated through a Kaplan-Meier curve observed in Figure.

Table 4 summaries the complications related to surgery of 65 patients with temporal LGG. However, it is important to note that as not all patients performed ophthalmological examination after surgery, it is difficult to provide exact rate of visual field defects. There was no surgical mortality in this study.

Histopathological diagnosis is described in Table 5.

Memory deficits were observed in $8(88.9 \%)$ of 9 patients $(13.8 \%)$ in whom subtotal resection of mesial structures was performed due to the dominance of memory, although tumor involvement was documented. Partial recovery of memory was noted in seven patients during follow up, however not reaching the normal limits for age. Of those patients with tumor on the non-dominant side, memory was shown to be preserved during follow up and all returned to work and normal daily life.

Table 1. Clinical findings of 65 patients operated with temporal LGG.

\begin{tabular}{lc}
\hline & Number of cases/\% \\
\hline Gender & \\
Female & $28 / 43.1$ \\
Male & $37 / 56.9$ \\
Mean age at surgery (years) & $32.3 \pm 8.4(9-68$ years) \\
Mean age at seizure onset (years) & $25.7 \pm 9.2(11-66$ years) \\
Seizure frequency/months & $18.2 \pm 38.7(1-120)$ \\
Time from seizure onset to surgery (years) & $9.4 \pm 6.9(1-27$ years) \\
Seizure type & \\
Partial complex & $46 / 70.8$ \\
Tonic-clonic generalized & $17 / 26.2$ \\
Multiple & $2 / 3.0$ \\
EEG Findings & $51 / 78.5$ \\
Lateralized & $51 / 100$ \\
Concordant ${ }^{a}$ & $8 / 12.3$ \\
Bilateral & $6 / 9.2$ \\
Normal & \\
Hemispheric dominance & $4 / 6.2$ \\
Right & $61 / 93.8$ \\
Left & $6.9 \pm 4.3(1-12$ years) \\
Mean follow-up (years) &
\end{tabular}

Table 2. Surgical findings of 65 patients operated with temporal LGG.

Number of cases/\%

\begin{tabular}{|c|c|}
\hline \multicolumn{2}{|l|}{ Side of surgery } \\
\hline Right & $39 / 60.0$ \\
\hline Left & $26 / 40.0$ \\
\hline Total resection & $56 / 86.2$ \\
\hline Partial resection & $9 / 13.8$ \\
\hline \multicolumn{2}{|l|}{ Location } \\
\hline \multicolumn{2}{|l|}{ Right side } \\
\hline Mesial removed & $35 / 89.7$ \\
\hline Mesial Spared & $4 / 10.3$ \\
\hline \multicolumn{2}{|l|}{ Left side } \\
\hline Mesial removed & $16 / 61.5$ \\
\hline Mesial Spared & $10 / 38.5$ \\
\hline \multicolumn{2}{|l|}{ Sub-location } \\
\hline Mesial only & $28 / 43.1$ \\
\hline Mesial removed & $26 / 92.9$ \\
\hline Mesial Spared & 2/7.1 \\
\hline Lateral only & $13 / 20$ \\
\hline Mesial removed & $2 / 15.4$ \\
\hline Mesial Spared & $11 / 84.6$ \\
\hline Whole temporal & $24 / 36.9$ \\
\hline Mesial removed & $17 / 70.8$ \\
\hline Mesial Spared & $7 / 29.2$ \\
\hline Recurrence or residue & $11 / 16.9$ \\
\hline Reoperation & 2/3.1 \\
\hline
\end{tabular}

LGG: low-grade glioma.

Table 3. Seizure outcome of 65 patients operated with temporal LGG.

\begin{tabular}{lcccc}
\hline & \multicolumn{4}{c}{ Engel Classification (n/\%) } \\
\cline { 2 - 5 } & I & II & III & IV \\
\hline Side of surgery & & & & \\
$\quad$ Right (39/60.0) & $26 / 66.7$ & $10 / 25.6$ & $2 / 5.1$ & $1 / 2.6$ \\
$\quad$ Left (26/40.0) & $16 / 61.5$ & $7 / 26.9$ & $2 / 7.7$ & $1 / 3.8$ \\
Extension of resection* & & & & \\
Total (56/86.2) & $39 / 69.6$ & $14 / 25.0$ & $2 / 3.6$ & $1 / 1.8$ \\
$\quad$ Partial (9/13.8) & $3 / 33.3$ & $3 / 33.3$ & $2 / 22.2$ & $1 / 11.1$ \\
Age group & & & & \\
> 40 years (24/36.9) & $15 / 62.5$ & $7 / 29.2$ & $1 / 4.2$ & $1 / 4.2$ \\
$\quad$ < 40 years (41/63.1) & $27 / 65.9$ & $10 / 24.4$ & $3 / 7.3$ & $1 / 2.4$ \\
Mesial structures & & & & \\
$\quad$ Removed (51/78.5) & $33 / 64.7$ & $14 / 27.4$ & $4 / 7.8$ & $0 / 00.0$ \\
$\quad$ Spared (14/21.5) & $9 / 64.3$ & $3 / 21.4$ & $0 / 00.0$ & $2 / 14.3$ \\
Total (n = 65) & $42 / 64.6$ & $17 / 26.2$ & $4 / 6.2$ & $2 / 3.1$ \\
\hline LGG: low-grade glioma; * Fisher exact test, $p<0.05($ Engle I).
\end{tabular}

\section{DISCUSSION}

Most patients with LGG experience epileptic seizures as a presenting symptom ${ }^{16,17,18}$. Clinically, tumor-related seizures manifest as simple or complex partial seizures with or without secondary generalization ${ }^{19}$ and, in more than $50 \%$ of cases, are pharmacoresistant ${ }^{20}$. When uncontrolled, tumor-related epilepsy affects patients' quality of life, causes 


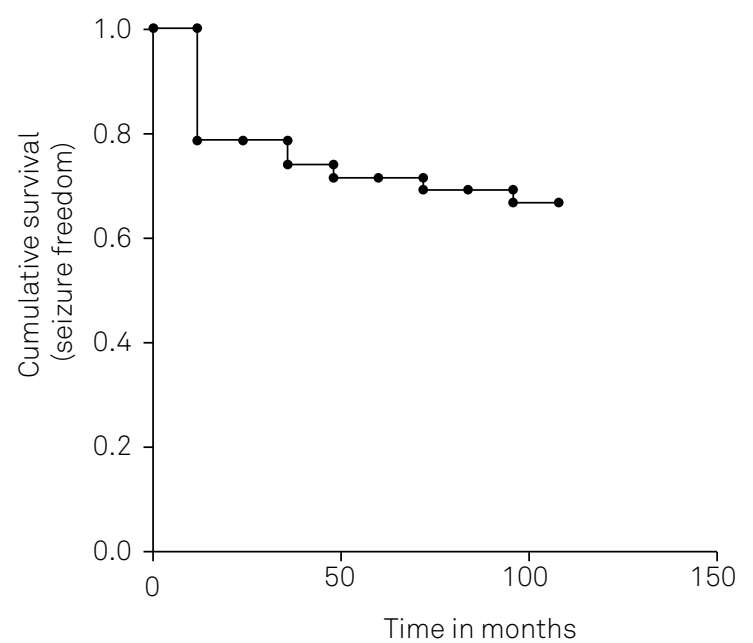

Figure. Kaplan-Meier curve showing the seizure-free survival rate over time of 65 patients with temporal LGG submitted to surgical treatment.

Table 4. Complications related to surgery of 65 patients with temporal LGG.

\begin{tabular}{lc} 
& Number of cases/\% \\
\hline Infection & $8 / 57.1$ \\
Contralateral hemiparesis & $2 / 14.3$ \\
Visual field deficits & $4 / 28.6$ \\
Total & $14 / 21.5$ \\
\hline
\end{tabular}

LGG: low-grade glioma.

Table 5. Histopathological diagnosis of 65 patients operated with temporal LGG.

\begin{tabular}{lc}
\multicolumn{1}{c}{ Tumor (WHO grade) } & Number of cases/\% \\
\hline Ganglioglioma (I) & $24 / 36.9$ \\
DNETa $^{\text {(I) }}$ & $14 / 21.5$ \\
Diffuse astrocytoma (II) & $11 / 16.9$ \\
Oligodendroglioma (II) & $9 / 13.8$ \\
Pleomorphic xanthoastrocytoma (II) & $4 / 6.2$ \\
Others $^{\text {b }}$ & $3 / 4.6$ \\
\hline
\end{tabular}

a Dysembroplastic neuroepithelial tumor; : mixed oligodendroglioma/astrocytoma and astroblastoma; LGG: low-grade glioma.

cognitive deterioration, and may result in significant morbidity $^{21,22}$. In the present study, we have shown that males were more affected than females without a clear explanation and clinical symptoms usually appear in young age. Partial complex seizures were the most common type in our study and in similar investigations in other epilepsy centers ${ }^{10,11,12,13,19}$.

There are still several controversies regarding surgical treatment of patients with temporal LGG and no standard guide exists showing the best surgical approach to this patients. There have been mainly four types of surgery including standard anterior temporal resection only, standard anterior temporal with amygdalohippocampectomy, extended lesionectomy with amygdalo-hippocampectomy and extended lesionectomy $19,23,24,25,26$. We generally performed the following protocol: in non-dominant temporal lobe, tumor removal was done by standard anterior temporal with amygdalohippocampectomy; but in case of dominant side, we respected the mesial structures and performed extended lesionectomy. When the mesial structures where involved by the tumor in the dominant side, we generally performed only partial resection $(1-2 \mathrm{~cm})$ of the mesial components and followed the patient radiologically. This protocol is in agreement with groups that believe that tumors should be removed totally when feasible without adding any neurological deficits ${ }^{19}$. In the present study, fifty six patients $(86.2 \%)$ had total resection and 9 patients (13.8\%) partial resection, one in the right lobe and eight in the left. Memory deficits were observed in eight (88.9\%) out of 9 patients. As long as the decision of whether or not partially remove the mesial structures on the dominant side affected by tumor is an extremely controversial theme on the international literature, we based our decision four mean topics: (1) according to the patient's wishes, (2) amount of involvement of the mesial structures, (3) clinical conditions of the patient and (4) the functional reserve of memory established by pre-operative neuropsychological evaluation. Although a systematic scheme was propose, still more than $85 \%$ of patients evolved memory deficits. We believe a great amount of investigational studies addressing this issue are necessary to improve tumor control and quality of life of patients involvement of mesial structures on the dominant side.

Regardless of the type of resection, most investigations have proved surgery as an effective mean to control seizure in patients with temporal LGG $(10-14,19,20)$. Early operative intervention $^{12}$, gross-total resection ${ }^{14}$, shorter history of seizure ${ }^{27,28}$ and preoperative seizure frequency ${ }^{28}$ are other factors associated with seizure freedom in the surgical resection of temporal LGG. We had satisfactory rate of favorable seizure outcome, reaching $69.6 \%$ of seizure freedom (Engel I) and $88.8 \%$ of good clinical control (Engel I and II), which was in agreement with other clinical studies ${ }^{10,11,12,13,14,19,20}$. The extension of resection proved to be a statistically significant factor associated directly with better seizure outcome. In the present study, postoperative Engel I was observed in 39 patients (69.6\%) with total resection and in only 3 (33.3\%) patients with partial resection (Fisher exact test, $\mathrm{p}$-value $=0.0435$ ). The authors believe that removing as much tumor as possible, the surgeon will not only eliminate the epileptogenic action of tumor compression over the parenchyma, but also reduce the effect of epileptogenic substances released by glioma cells, such as glutamate, that have been proved as a possible cause of seizures 8 .

Few discrepancies exist in the histopathological diagnosis of temporal LGG and most studies agree that gangliogliomas are the most common tumor type followed by DNET, astrocytomas and oligodendrogliomas ${ }^{4,19,28,29}$. Our results reinforces that gangliogliomas are the leading neoplastic cause of refractory epilepsy of the temporal lobe. Glagliogliomas comprised $36.9 \%$, followed by DNET with $21.5 \%$, diffuse 
astrocytoma with $16.9 \%$, oligodendroglioma with $13.8 \%$ and pleomorphic xanthoastrocytoma with $6.2 \%$.

There are several methodological aspects in the present findings, which should be interpreted in the context of a number of limitations. Firstly, this study is a non-randomized retrospective investigation performed in a highly selected population of a tertiary epilepsy center. Secondly, these findings cannot be generalized for all types of tumors since only patients with LGG where included on the present investigation. On the other hand, the present study described the surgical outcomes of a relatively large number of patients that underwent surgery due to this pathology for a relatively extended follow-up duration.

In conclusion, the present study highlights that temporal LGGs are a significant etiology of intractable epilepsy and gross-total resection of the lesion is a critically important factor in achieving seizure-freedom.

\section{References}

1. Bauer R, Ortler M, Seiz-Rosenhagen M, Maier R, Anton JV, Unterberger I. Treatment of epileptic seizures in brain tumors: a critical review. Neurosurg Rev. 2014;37(3):381-8. doi:10.1007/s10143-014-0538-6

2. Shields LB, Choucair AK. Management of low-grade gliomas: a review of patient-perceived quality of life and neurocognitive outcome. World Neurosurg. 2014;82(1-2):e299-309. doi:10.1016/j.wneu.2014.02.033

3. Maurice C, Mason WP. Seizure management in patients with gliomas. Expert Rev Neurother. 2014;14(4):367-77. doi:10.1586/14737175.2014.890890

4. Ruban D, Byrne RW, Kanner A, Smith M, Cochran EJ, Roh D et al. Chronic epilepsy associated with temporal tumors: long-term surgical outcome. Neurosurg Focus. 2009;27(2):E6. doi:10.3171/2009.5.FOCUS0998

5. Giulioni M, Rubboli G, Marucci G, Martinoni M, Marliani AF, Bartiromo F et al. Focal epilepsies associated with glioneuronal tumors: review article. Panminerva Med. 2013;55(2):225-38

6. Giulioni M, Marucci G, Martinoni M, Marliani AF, Toni F, Bartiromo F et al. Epilepsy associated tumors: Review article. World J Clin Cases. 2014;2(11):623-41. doi:10.12998/wjcc.v2.i11.623

7. Iuchi T, Hasegawa Y, Kawasaki K, Sakaida T. Epilepsy in patients with gliomas: incidence and control of seizures. J Clin Neurosci. 2015;22(1):87-91. doi:10.1016/j.jocn.2014.05.036

8. Buckingham SC, Campbell SL, Haas BR, Montana V, Robel S, Ogunrinu T et al. Glutamate release by primary brain tumors induces epileptic activity. Nat Med. 2011;17(10):1269-74. doi:10.1038/nm.2453

9. Breemen MS, Wilms EB, Vecht CJ. Epilepsy in patients with brain tumours: epidemiology, mechanisms, and management. Lancet Neurol. 2007;6(5):421-30. doi:10.1016/S1474-4422(07)70103-5

10. Babini M, Giulioni M, Galassi E, Marucci G, Martinoni M, Rubboli $G$ et al. Seizure outcome of surgical treatment of focal epilepsy associated with low-grade tumors in children.J Neurosurg Pediatr. 2013;11(2):214-23. doi:10.3171/2012.11.PEDS12137

11. Englot DJ, Han SJ, Berger MS, Barbaro NM, Chang EF. Extent of surgical resection predicts seizure freedom in low-grade temporal lobe brain tumors. Neurosurgery. 2012;70(4):921-8. doi:10.1227/NEU.0b013e31823c3a30

12. Englot DJ, Berger MS, Barbaro NM, Chang EF. Factors associated with seizure freedom in the surgical resection of glioneuronal tumors. Epilepsia. 2012;53(1):51-7. doi:10.1111/j.1528-1167.2011.03269.x

13. Phi JH, Kim SK, Cho BK, Lee SY, Park SY, Park SJ et al. Long-term surgical outcomes of temporal lobe epilepsy associated with low-grade brain tumors. Cancer. 2009;115(24):5771-9. doi:10.1002/cncr.24666

14. Englot DJ, Berger MS, Barbaro NM, Chang EF. Predictors of seizure freedom after resection of supratentorial low-grade gliomas: a review. J Neurosurg. 2011;115(2):240-4. doi:10.3171/2011.3.JNS1153

15. lachinski RE, Meneses MS, Simão CA, Rocha SF, Braga FO, Kowacs PA. Patient satisfaction with temporal lobectomy/selective amygdalohippocampectomy for temporal lobe epilepsy and its relationship with Engel classification and the side of lobectomy. Epilepsy Behav. 2014;31:377-80. doi:10.1016/j.yebeh.2013.09.022
16. Liigant A, Haldre S, Oun A, Linnamägi U, Saar A, Asser T et al. Seizure disorders in patients with brain tumors. Eur Neurol. 2001;45(1):46-51. doi:10.1159/000052089

17. Lynam LM, Lyons MK, Drazkowski JF, Sirven JI, Noe KH, Zimmerman RS et al. Frequency of seizures in patients with newly diagnosed brain tumors: a retrospective review. Clin Neurol Neurosurg. 2007;109(7):634-8. doi:10.1016/j.clineuro.2007.05.017

18. Rosati A, Tomassini A, Pollo B, Ambrosi C, Schwarz A, Padovan A et al. Epilepsy in cerebral glioma: timing of appearance and histological correlations. J Neurooncol. 2009;93(3):395-400. doi:10.1007/s11060-009-9796-5

19. Kemerdere R, Yuksel O, Kacira T, Yeni N, Ozkara C, Tanriverdi T et al. Low-grade temporal gliomas: surgical strategy and long-term seizure outcome. Clin Neurol Neurosurg. 2014;126:196-200. doi:10.1016/j.clineuro.2014.09.007

20. Rudà R, Bello L, Duffau H, Soffietti R. Seizures in low-grade gliomas: natural history, pathogenesis, and outcome after treatments. Neuro-oncol. 2012;14 Suppl 4:iv55-64. doi:10.1093/neuonc/nos199

21. Aaronson NK, Taphoorn MJ, Heimans JJ, Postma TJ, Gundy CM, Beute GN et al. Compromised health-related quality of life in patients with low-grade glioma. J Clin Oncol. 2011;29(33):4430-5. doi:10.1200/JC0.2011.35.5750

22. Taphoorn MJ, Klein M. Cognitive deficits in adult patients with brain tumours. Lancet Neurol. 2004;3(3):159-68. doi:10.1016/S1474-4422(04)00680-5

23. Hu WH, Ge M, Zhang K, Meng FG, Zhang JG. Seizure outcome with surgical management of epileptogenic ganglioglioma: a study of 55 patients. Acta Neurochir (Wien). 2012;154(5):855-61. doi:10.1007/s00701-011-1259-z

24. Southwell DG, Garcia PA, Berger MS, Barbaro NM, Chang EF. Long-term seizure control outcomes after resection of gangliogliomas. Neurosurgery. 2012;70(6):1406-13. doi:10.1227/NEU.0b013e3182500a4c

25. Wallace D, Ruban D, Kanner A, Smith M, Pitelka L, Stein $J$ et al. Temporal lobe gangliogliomas associated with chronic epilepsy: long-term surgical outcomes. Clin Neurol Neurosurg. 2013;115(4):472-6. doi:10.1016/j.clineuro.2012.05.034

26. Wallace DJ, Byrne RW, Ruban D, Cochran EJ, Roh D, Whisler WW Temporal lobe pleomorphic xanthoastrocytoma and chronic epilepsy: long-term surgical outcomes. Clin Neurol Neurosurg. 2011;113(10):918-22. doi:10.1016/j.clineuro.2011.06.001

27. Chang EF, Potts MB, Keles GE, Lamborn KR, Chang SM, Barbaro NM et al. Seizure characteristics and control following resection in 332 patients with low-grade gliomas. J Neurosurg. 2008;108(2):227-35. doi:10.3171/JNS/2008/108/2/0227

28. Khajavi K, Comair YG, Wyllie E, Palmer J, Morris HH, Hahn JF. Surgical management of pediatric tumor-associated epilepsy. J Child Neurol. 1999;14(1):15-25. doi:10.1177/088307389901400102

29. Vannemreddy PS, Kanner AM, Smith MC, Rossi M, Wallace D, Vannemreddy $\mathrm{SN}$ et al. Chronic epilepsy due to low grade temporal lobe tumors and due to hippocampal sclerosis: do they differ in post-surgical outcome? J Neurooncol. 2013;115(2):225-31. doi:10.1007/s11060-013-1217-0 